\title{
CHILDREN'S THINKING. CLOUDS, RAIN, AND RAINBOW IN CHILDREN'S EXPLANATIONS
}

\author{
Eve Kikas
}

\begin{abstract}
The article describes the learning process of children, and the associated difficulties in the transfer from everyday thinking to scientific. Everyday explanations (direct descriptions of phenomena, fragments heard from adults, analogy-based explanations) are prevalent in preschool children. In school, children begin to learn scientific (non-experiential) knowledge and develop the scientific level of thinking. This is a long and time-consuming process, in the course of which children continue to use everyday explanations, adding to them synthetic concepts and explanations. The relevant theory is illustrated by analysing the explanations of children with regard to clouds and rain as conventional meteorological phenomena, and the rainbow as an extraordinary and attractive object which deserves attention. Individual interviews were conducted with 116 primary school students. The results show that everyday and synthetic explanations are predominant in primary school children, with the relevant reasons being pointed out.
\end{abstract}

Key words: children's thinking, everyday concepts, scientific concepts, clouds, synthetic concepts, rain, rainbow

People get information about the world from different sources (e.g., observing what is going on, watching films, reading books, listening to others), and this information is conceptualised, based on earlier knowledge and its structure. Frequently, people have difficulties with interpreting scientific, abstract information which is mediated by signs. This information is modified and only afterwards synthesised with one's earlier experience, which gives a feeling of understanding (see Chinn \& Brewer 2000; Chinn \& Malhotra 2002).

There are abundant studies on children's conceptions and their development in the area of elementary astronomy (e.g., Brewer 2008; Hannust \& Kikas 2007; Kikas 2003, 2005; Nobes \& Martin et al. 2005; Panagiotaki \& Nobes et al. 2008; Straatemeier \& van der Maas et al. 2008). Somewhat surprisingly, less attention has been paid to the easily and frequently observable weatherrelated phenomena. In the article, I first describe the children's learning process and difficulties regarding the transition from the everyday to scientific 
level of thinking. In the second part, I illustrate the theory, analysing children's explanations about clouds and rain as a daily phenomena and rainbow as a rare yet striking object which tends to attract everyone's attention.

\section{THINKING IN EVERYDAY AND SCIENTIFIC CONCEPTS}

Lev Vygotsky (Vygotsky 1934/1997; Vygotsky \& Luria 1930/1994) was the first who differentiated between everyday and scientific concepts. Later, Aaro Toomela (2003) has further developed the relevant theory and classification. Information, coded in everyday concepts, is explicitly based on senses or on the information that may be understood as a direct perceivable experience. These concepts, being experiential, based on perception, and not conscious, are the first to develop in children.

Information in scientific concepts is verbal - the information is coded and organised in sign systems (mainly in spoken language) (see Toomela 2003; Vygotsky 1934/1997). These concepts have a formal-logical hierarchical structure. When thinking in everyday concepts, a person is limited to the perceivable, experiential world, while thinking in scientific concepts enables one to "see beyond the perceptible, see the invisible". Knowledge coded in words is generalised in scientific concepts which enables to give new meanings to perceptible phenomena (Nelson 2003; Toomela 2003). This analysis is based on formal logic; authority or personal experiences cease to be sufficient arguments on which to base one's explanations. Persons can justify the bases of formation of scientific concepts, which means that concepts and the thinking process have become conscious. Scientific concepts are not exclusively those from the field of science although all concepts from science (i.e., in this article concepts related to weather) are scientific.

\section{Everyday thinking and children's explanations}

Starting from the birth, babies pay attention to objects and relations, observe and discover regularities. However, they do not learn only by themselves. Children hear how other people name objects and phenomena and based on these two - visible and auditory - sources, develop their everyday concepts (Kikas 2003, 2005; Nelson 2003, 2007; Vygotsky 1934/1997). Listening to adults' speech and the interpretation thereof is of great relevance when developing new explanations. Indeed, adults are the ones who provide children with words, answering children's questions and helping to structure the information. Through these activities, children develop everyday concepts and explanations 
about the world - this knowledge is about the visible and/or experiential world but is also mediated by signs. Children may have everyday knowledge of the fact that everything in the world is not directly observable, yet they lack the tools for thinking to conceptualise the information about this non-perceptual world.

When describing the phenomena that are not directly perceptible, children sometimes use exact wordings heard from adults (so-called verbalisms). It is easily seen among young children - at first they imitate adults' speech quite exactly, repeating the fragments they have heard. Here, speaking and thinking is strictly based on the perceptible, using everyday concepts. However, even in this instance, the meanings of children and adults overlap only partly - children use a lot of over- and under-generalisations. During their third year of age, children start playing with language - they create new expressions they have not heard from others (e.g., they over-generalise grammar rules, using expressions like "we bringed pillow" or develop new words). In order for the children to better understand the world, it is important that they start asking about the more precise meaning of words and explanations with regard to phenomena (see Wellman \& Hickling et al. 1997). It means that already at preschool age children actively search for explanations and do not merely repeat (also in a simplified manner) what they have heard. However, verbalisms (fragments heard from adults) are used later as well. This is clearly observable in school when children start to speak scientific language. In this process, children sometimes imitate simply the form, not paying attention to the content (e.g., they emphasise the usage of "because", or use other complicated terms, however, in a wrong sense) (see Wertsch 1991).

Phenomena that are not directly perceptible may also be conceptualised by way of drawing analogies from the perceptible and experiential world. These kinds of explanations become available only after children are able to compare different phenomena and transfer features from one sphere to another one. Already 2-3-year-old children make analogies based on perceptual features, for instance saying that "the Sun is like a ball". Preschool children frequently use analogies in their explanations.

Besides visual perception, analogies are made by relying on a mechanism. Little children frequently use egocentric explanations, which, in essence, are analogies from what has happened personally to them. Piaget (1954) described this tendency as childhood egocentrism (a tendency to see the world only from one's own point of view), and related it to animistic explanations (a tendency to add to non-living objects features characteristic only to living things). For instance, children also attribute feelings, intentions and desires to inanimate objects, and provide psychological explanations to the (causal) changes in the 
physical world (e.g., "the Sun shines to make the life of people more comfortable", see Kikas 2005).

The formation and regularities of everyday concepts are not conscious. These explanations may vary in time and by topic. A child may start explaining the phenomenon with one reason and then turn to the other (see Vygotsky 1934/ 1997). For instance, a child may explain that it is night-time when the Sun is behind clouds and daytime so that children could play at this time. Siegler $(1996,2007)$ has shown the variety and heterogeneity in children's thinking (e.g., in explanations, problem solving strategies).

\section{Learning scientific explanations and thinking in scientific concepts}

Contemporary scientific explanations are mediated by symbols (e.g., language, models, mathematical formulae); in order to understand a seemingly simple phenomenon, it is sometimes necessary to know theories that have developed in the course of centuries (Kikas 2003; Nelson 2003; Wertsch 1998). New mediators enable the explaining of the world in a more integrated manner, allowing for new predictions (cf. the theories of Newton and Einstein). At the same time, these mediators limit the group of people who understand them due to the need for more specific and complicated preliminary knowledge and skills in using symbols. Explanations make use of scientific concepts - not only the words the referent of which is perceptible but also words through which other words are explained. In other words - the symbolic world differentiates from the material world (Vygotsky \& Luria 1930/1994). Similarly to the way material tools (e.g., cars, tractors) help people act quicker and more effectively or learn about new aspects of the world (e.g., telescope, microscope), the theories are also "tools" that help us understand the non-perceptible phenomena as space, galaxy, electrons, atoms (Vygotsky 1931/1983; Wertsch 1998). Both types of tools have accumulated the knowledge built by earlier generations. Children learn scientific knowledge not through their own experiments but from other people who help to conceptualise symbols in the way accepted in culture (Kikas 2003; Nelson 2003). At the moment when children start to learn such knowledge, they have developed their own everyday explanations, which form the bases in which to integrate and interpret new information. However, in children as well as in adults, their preliminary knowledge affects how they interpret the new information (e.g., Ackerman \& Beier 2006; Kendeou \& van den Broek 2005).

The learning process is time-consuming and consists of several stages. Both adults and children cannot learn ready-made explanations, either from other 
people or from books; it is not possible to "fill the heads like empty bottles". People have to interpret the explanations, in the background of their existing knowledge and structure of thinking, and, thereafter, integrate the new knowledge in this structure. Vygotsky (1934/1997) stressed that in the beginning of the learning process people develop pseudo-concepts, which externally seem as scientific concepts (words heard from adults) but are in essence everyday concepts. Children easily learn a new word but interpret it relying on their daily experience. Similarly to young children who use fragments of sentences heard from adults, schoolchildren repeat complex scientific explanations heard from their parents/teachers, doing it mechanically and in limited contexts (see Kikas 2003, 2005; Wertsch 1991). Although it seems as if a child thinks similarly to an adult (i.e., has learnt knew knowledge), he/she may use words (expressions) in a completely different sense than adults do. Knowledge becomes more precise when talking to other people, whereby a child needs to make him or herself more understandable to others, not only interpret the information by him/herself. It means that for learning, not only internalising but also externalising process is of importance, and actually these may be dealt with as two sides of the same developmental process (see also Nelson 2007).

When children do not have enough time for conceptualising the new information or when they lack necessary tools (knowledge or skills) for creating relations, pseudo-concepts develop into synthetic concepts (i.e., concepts, modified and constructed based on experience), also referred to as misconceptions (stressing the fact that these concepts are incorrect from the point of view of contemporary science), distorted knowledge, pseudo-scientific concepts (e.g., Driver \& Squirer et al. 1994; Glynn \& Duit 1995; Henriques 2000). In essence, these are still pseudo-concepts - their format and content are different. At first, synthetic concepts seem similar to scientific concepts and only after asking questions that demand more precise answers and giving novel problems may it turn out that the content of the concepts differs from that of the scientific one (see Kikas 2005). During the learning process, the scientific explanation may become altered as new information is interpreted, making it more suitable with earlier daily experience, which gives the feeling of understanding (see Chinn \& Brewer 2000; Driver \& Squirer et al. 1995; Kikas 2003, 3005). Additionally, schoolchildren use fragments of explanations, heard from teachers (verbalisms), and children do not distrust these due to the authority of the teacher as a source of knowledge (see Kikas 2005).

Only when children have enough time for learning, when they are provided with a variety of tasks and possibilities to discuss what they have learnt, they may develop scientific concepts, i.e., concepts similar to those used by adults. 
It is often difficult to differentiate between synthetic concepts, verbalisms, and scientific concepts. Children have difficulties with wordings and explanations, and thus they use fragments heard from somewhere, and this suffices for adults. Parents are happy when their children provide such wise and complicated explanations, teachers are proud that children have understood the topic. Children's explanations (their level, integrity, complexity) are influenced by situations, people, and questions (Siegler 1996). It is therefore important to study children's concepts with different methods and tools (various questions and tasks, in groups and individually). The knowledge of children's concepts is of practical importance in school - the content and structure of daily knowledge influences the way children interpret new information while learning in school.

To sum up - preschool children use mainly everyday concepts and explanations, in school children start to learn scientific (non-perceptible) knowledge which gives rise to the development of scientific concepts and scientific thinking. However, this is a time-consuming and complicated process in the course of which children would still use everyday explanations, developing synthetic concepts and explanations in addition to the latter. It is possible to differentiate between three types of explanations, described in a developmental sequence in Table 1.

\section{CLOUDS, RAIN, AND RAINBOW}

Everyone has probably enjoyed moving clouds in the sky. Children often look at clouds together with their parents or teachers. Tiivi Marken studied 44 fiveand-seven-year-old Estonian kindergarten children (unpublished data) and found

Table 1. Types of explanations

\begin{tabular}{|c|c|}
\hline Type & Description \\
\hline $\begin{array}{l}\text { Everyday } \\
\text { explanations }\end{array}$ & $\begin{array}{l}\text { These explanations are developed, based on child's own experience and } \\
\text { perception. These include: } \\
\text { - Descriptions of phenomenon/object } \\
\text { - Fragments heard from adults (also, religious descriptions, myths) } \\
\text { - Direct analogies } \\
\text { - Person-based (egocentric) analogies }\end{array}$ \\
\hline $\begin{array}{l}\text { Synthetic or } \\
\text { constructed } \\
\text { explanations }\end{array}$ & $\begin{array}{l}\text { These explanations are developed through synthesising one's own experience and } \\
\text { learnt verbal knowledge. Through this process a child conceptualises the } \\
\text { scientific information. Here one can see that although a child possesses correct } \\
\text { factual knowledge, he/she is not able to use it. These include: } \\
\text { - Analogies that use scientific information } \\
\text { - Incomplete and contradictory explanations that use scientific } \\
\text { information }\end{array}$ \\
\hline $\begin{array}{l}\text { Scientifically } \\
\text { correct } \\
\text { explanations }\end{array}$ & $\begin{array}{l}\text { Explanations that are concor dant with contemporary scientific explanations; } \\
\text { different parts are consistent. }\end{array}$ \\
\hline
\end{tabular}


that 18 children stated that they had observed clouds either with a parent or a teacher, and 20 children added that adults had given explanations as well.

Scientists examine clouds from different aspects, analysing their origin, composition, structure, differentiating between types (Jürissaar). This knowledge is important for weather broadcasting. Clouds are not always related to rain, although the opposite is true - there is no rain from a cloudless sky. To understand the mechanism of precipitation, it is necessary to know about conservation of matter, evaporation etc., it means - about physical processes which are taught at school in several grades.

The rainbow is (depending on a season and country) a relatively rare optical phenomenon, which, however, attracts attention due to its colourfulness. Parents show it to their children already at a very young age. In the abovementioned study, Marken found that 15 children remembered that they had observed the rainbow together with parents or teacher, 20 children added that adults explained the reason for the rainbow.

As for the forming of a rainbow, sunrays refract and reflect from raindrops, knowledge of optical laws is necessary for understanding the mechanism of its formation. Usually children learn at school (see also Loks \& Loks 2003) about the seven colours (red, orange, yellow, green, blue, indigo, and violet) of the rainbow, although, in a majority of instances, it is impossible to differentiate between them all in reality. Rainbow as a phenomenon has been analysed by scientists, Aristotle (explained the rounded shape of the rainbow), Isaac Newton (the origin of colours), Rene Descartes (refraction of light beams in the rainbow) (see Vikerkaar)

Children's conceptions about clouds and rain have been studied since Piaget (1930), yet surprisingly there are only a few studies about the rainbow. Several overviews about children's misconceptions have been compiled (e.g., Driver \& Squires et al. 1994; Henriques 2000), informative for teachers who teach the relevant topic. Likewise, examination of such explanations gives information about children's thinking. So far, however, there are few papers which analyse and explain the formation of misconceptions bearing in mind the peculiarities of children's development and learning.

Below I describe examples from the empirical study carried out in Estonian primary grades. Schoolchildren (50 second graders and 66 fourth graders) were studied by Sigrid Kruus and Elina Malleus. Children's answers were divided into four categories. In addition to the three types of explanations described in Table 1, we added the missing-answers category, i.e., when the child said "Don't know" or nothing at all. All the children had studied the topics of clouds, rain and other meteorological phenomena in grade 2, prior to conducting the interview (see Elvisto \& Kuurme et al. 2002; Loks \& Loks 2003). Fourth graders 

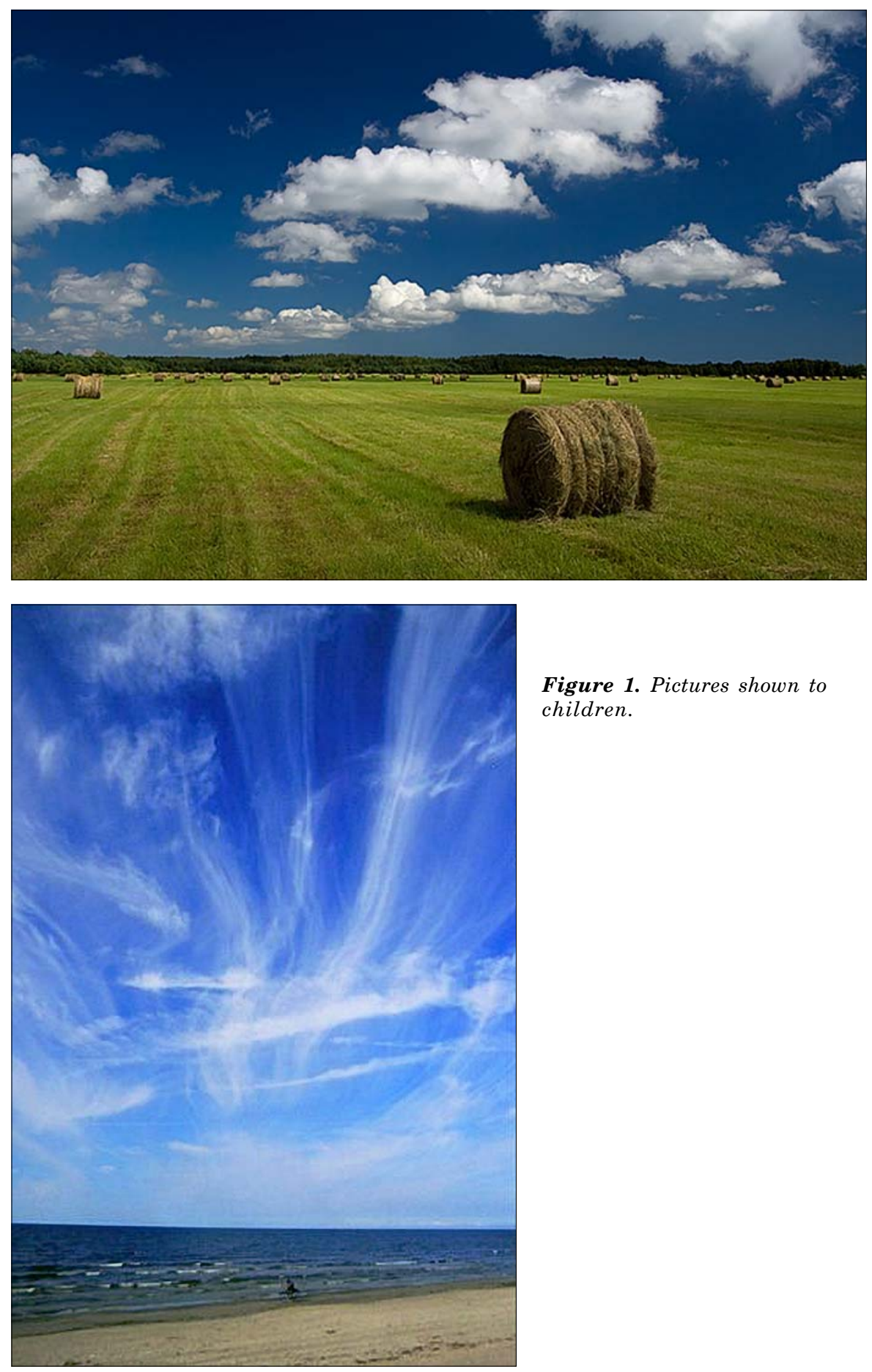

Figure 1. Pictures shown to children. 
had not officially studied about the topics more than two years ago since their work in second grade. As the distribution of answers did not differ between grades, I describe the answers together.

\section{Clouds and rain in children's explanations}

In earlier studies children had been asked in a general form "What are clouds made of?", in this study, however, the questions were made more specific. Each child was shown three pictures of different types of clouds (cumulus, cirrus, rainclouds, see Fig. 1) and were asked (at the same time when the child looked at the picture), "What are these clouds made of?". This made it possible to analyse whether the appearance of the clouds (e.g. cirrus resembles bird's feathers, but cumulus - cotton wool) influences the answers and whether the answers given to different questions are concordant. The number of children who either did not answer, provided everyday, synthetic, and scientific answers is shown in Table 2 .

Table 2. Distribution of different types of answers: Clouds

\begin{tabular}{lcccccccc}
\hline & \multicolumn{3}{c}{ What is cloud made of? } & \multicolumn{3}{c}{ How does "this" get into the cloud? } \\
\hline & $\begin{array}{c}\text { Don't } \\
\text { know }\end{array}$ & $\begin{array}{c}\text { Every- } \\
\text { day }\end{array}$ & $\begin{array}{c}\text { Syn- } \\
\text { thetic }\end{array}$ & Scien- & Don' t & Every- & Syn- & Scien- \\
tific & know & day & thetic & tific \\
Cumulus & 9 & 27 & 37 & 43 & 28 & 36 & 15 & 37 \\
Cirrus & 14 & 23 & 40 & 39 & 35 & 33 & 22 & 26 \\
Raincloud & 8 & 24 & 55 & 29 & 28 & 40 & 22 & 26 \\
\hline
\end{tabular}

Note. Number of children who gave a specific type of answer

Friedman ANOVA showed that there were no statistically significant differences between answers given to different types of clouds, $\chi^{2}(2)=1.78, p=0.41$. Additionally, I compared scientific answers given to different questions by pairs, using the Cochran Q-test. These analyses did not show any statistically significant differences either. It means that children's answers to different types of clouds were relatively consistent regarding the form of answers (i.e., in using either everyday, synthetic, or scientific concepts). As seen from Table 2, more than a quarter of children gave simple everyday descriptions to the questions about the consistence of the cloud (illustrated by the picture). Less than half of the children gave scientific answers.

The majority of everyday answers were analogies with the visible: made of "smoke" (for cumulus 14, cirrus 15, and rainclouds 17), for cumulus, one additional answer was "cotton wool" (9 answers). There were also a few answers 
such as "marshmallow, rice, foam". In synthetic answers, clouds were identified with rain, which means that the children have possibly heard that rain comes from clouds (and therefore they state that clouds consist of rain). Additionally, children said that clouds are made of mist, which may be related to the knowledge that when mist rises, it might start raining. The number of such answers for cumulus was 21 , for cirrus 12 , and rainclouds 35 . In specific answers it was possible to note the impact of the exterior of a particular cloud - cirrus was related to air, for instance, with "air pressure, air, gas" given as answers (15 answers). Additionally, few children named different types of precipitation "thunderstorm, storm, snow" and meteorological phenomena "tornado, northern lights".

Friedman ANOVA did not show significant differences in the types of children's answers to the question "How did 'this' get into the cloud?", $\chi^{2}(2)=1.71$, $\mathrm{p}=0.42$. However, when comparing the amount of scientific answers given to different pairs of clouds with Cochran Q-test, it was found that more scientific answers were given to cumulus as compared with cirrus, $\mathrm{Q}(1)=7.12, \mathrm{p}<0.008$, and rainclouds, $Q(1)=5.76, p<0.016$. There was no statistically significant difference in the amount of scientific answers given to rainclouds and cirrus.

The next question was formulated depending on what the child had answered to the previous question. Problems with answering this question are related to difficulties in understanding how objects (e.g., water, cotton wool) get up into the sky as according to daily experience all objects fall down (see also Vosniadou 1994). It was easier to answer when the first answer had been "smoke" as children have seen smoke going up from chimneys. The majority of everyday answers comprised "smoke/dust goes up into the sky" (for cumulus 15 , cirrus 12 , and rainclouds 16 ). In a few answers, formation of clouds was related to someone's (e.g. the Sun) activity, but also, some stated that clouds come from above the distant sky (i.e., fall down as all objects). The more widespread synthetic answers differed depending on the type of the clouds. Children related the formation of cumulus with mist ("mist goes together or up", 8 answers) and of cirrus with wind ("wind blows up the steam, wind takes the clouds up", 9 answers). The explanations regarding the formation of rainclouds were more diverse: children emphasised the active role of the cloud ("clouds absorb humidity", 7 answers) and the role of warmth ("they form due to warmness and cold, clouds with plus and minus degrees collide, warm and cold clouds meet, rain goes inside them in cold weather", 5 answers). In these answers, children make analogies with perceptible phenomena and modify verbally heard information, or they do not provide the whole necessary information (i.e., their answers are incomplete). 
I also compared the concordance of answers given to two different questions. There were no differences between the right answers given to cumulus and rainclouds while in the case of cirrus, significantly more correct answers were given to the first than to the second question, $Q(1)=6.30, p<0.01$. In all categories, Friedman ANOVA showed statistically significant differences in the type of answers for cumulus, $\chi^{2}(1)=17.31, p<0.001$, cirrus, $\chi^{2}(1)=21.73$, $\mathrm{p}<0.001$, and raincloud, $\chi^{2}(1)=21.49, \mathrm{p}<0.001$. It means that children's answers are not concordant to the questions that are different yet related to the same type of cloud.

Questions about rain were general, and the methodology was similar to that used in earlier studies (see Driver \& Squires et al. 1994; Henriques 2000). First, children were asked "Where does rain come from?". Table 3 gives an overview of the number of children who did not answer, who gave everyday, synthetic, and scientific explanations. The correct answer was "from a cloud". A surprisingly large number of children answered from an everyday experiential level simply "from the sky" (16 children), and also "from somewhere far away", "from the space" and a few children used the analogy with crying: "these are angels' tears". In synthetic answers, the (incomplete) idea of the circulation of water is visible: "vanishes from the ground", "from the sea, river, a body of water". However, half of the children answered correctly (i.e., evaporates) to the question "How does rain get there?". Still, there were synthetic answers, related to the air as well: "when warm and cold airs collide, then drops are formed; through the air" (30 children) or "it is formed inside a cloud" (9 children). Answers to the question "Why does it start to rain?" were very diverse. There were everyday egocentric answers that related the reasons with the needs of people and nature, some named supernatural forces ("angels cry", "God is sad"), and also used analogy with melting ("cloud melts", "ice melts high up in the sky"). In synthetic explanations, children made use of the idea of steam and the water cycle ("steam changes into water", "water cycle proceeds", "in the rain there is more vapour"), clouds ("clouds meet and there is some kind of bonding") and air ("rain is made from mist with the help of warm air", "air pressure changes too quickly"). Friedman ANOVA determined statistically significant differences in answers to these three questions, $\chi^{2}(2)=51.13, \mathrm{p}<0.001$.

Table 3. Distribution of different types of answers: Rain

\begin{tabular}{lcccc}
\hline & Don't know & Everyday & Synthetic & Scientific \\
\hline Where does rain come from? & 25 & 34 & 28 & 29 \\
How does rain get there? & 7 & 9 & 39 & 61 \\
Why does it start raining? & 20 & 24 & 53 & 19 \\
\hline
\end{tabular}

Note. Number of children who gave a specific type of answer 


\section{Rainbow in children's explanations}

Pictures were used when studying Estonian schoolchildren's conceptions of the rainbow. Children were shown four pictures where the rainbow was not drawn but there were: 1) the Sun and clear sky, 2) rain and raincloud, 3) the Sun and white clouds, 4) the Sun, rain, and raincloud, and children were asked "In which case can we see the rainbow?" The majority of children chose the correct picture - 102 children (out of 116) chose the fourth picture, and only few either the second or third one. Similarly, in the case of the question "How is the rainbow formed?", the majority (97) of children described the situation correctly ("when the sun shines and it is raining, then the rainbow is formed"). Some synthetic answers were: "the Sun reflects on water and then the rainbow is formed in the sky" and "the rainbow is always in the sky but the Sun makes it visible". In their answers on the everyday conceptual level, children described the visible situation ("the Sun is in the sky"). The precise number of different types of answers is given in Table 4 .

Table 4. Distribution of different types of answers: Rainbow

\begin{tabular}{lcccc}
\hline & Don't know & Everyday & Synthetic & Scientific \\
\hline How is the rainbow formed? & 2 & 9 & 8 & 97 \\
What is the role of the Sun in this process? & 97 & 3 & 0 & 16 \\
What is the role of rain in this process? & 103 & 5 & 0 & 4 \\
$\begin{array}{l}\text { Sunlight is one-coloured. Why is the rainbow } \\
\text { multicoloured? }\end{array}$ & 31 & 12 & 51 & 22 \\
\hline
\end{tabular}

Note. Number of children who gave a specific type of answer

In contrast, there were only rare scientific answers to the question "How do the Sun and rain give birth to the rainbow?" Children were asked to explain separately as to what is the role of the Sun and rain in the formation of the rainbow. For the part of the Sun, 16 children explained that it gives the rainbow colours because light refracts and reflects on the drops of water and colours are formed, others gave everyday explanations "the Sun gives warmth", "the Sun gives glitter". To the similar question about the role of rain, only four children answered correctly. Few everyday explanations were that rain gives glitter and the arc-like form.

To the question "The sunlight is one-coloured, but how do we see different colours in the rainbow?", the right answers ("the sun reflects"; "when reflecting, different colours are seen under different angles"; "reflects like on a crystal") were given by 22 children. The majority of answers were synthetic, with several explanations telling that there are colours already existent in the rain, e.g., "there are colours in the rain/water, when the sun reflects, then the colours become visible and the rain starts to glitter" ( 29 children). The fact that 
light includes colours was explained in the following way: "light includes colours and each light-beam is of a different colour". Also, children associated reflection with other objects: "the Sun reflects from grass, flowers, etc." (12 children), and "the Sun gives yellow colour and rain blue, and then all the others come as well" ( 3 children), "the Sun has absorbed from nature all these colours" (3 children), "the colours depend on the distance of the Sun and the denseness of the rainbow" ( 1 child). Even some schoolchildren answered simply "because the rainbow is such a phenomenon" ( 6 children) and "it is so beautiful" (1 child).

\section{SUMIMARY}

Learning scientific knowledge is a time-consuming process, in the course of which the new, semiotically mediated information is integrated with earlier direct experience (see Kikas 2003; Vygotsky 1934/1997). Children are in difficulties with understanding new knowledge due to their preliminary everyday experiences and concepts (which, although widely used, may be inexact and unconscious), yet also due to the fact that there is not enough time in school for conceptualising knowledge and that children may lack necessary "tools" (theories, concepts) for explaining the phenomena (see also Vosniadou \& Ioannides et al. 2001). Likewise, teachers (and other adults, including scientists) have also difficulties in recognising what children have understood and what creates problems for them. Children are not very good at expressing their ideas, they may also be inconsistent in their explanations, use different and even partly contradictory explanations and repeat fragments of sentences heard from adults. Teachers may be so self-confident in their explanations that they do not see different possibilities for interpreting a phenomenon. Studies have shown that teachers do not know children's misconceptions and that they themselves possess misunderstandings of the topics they teach (e.g., Kikas 2004).

In the article I have described primary school children's answers to the questions about clouds, rain, and rainbow. All these children had previously learnt about weather related phenomena at school. It was shown that schoolchildren used all types of everyday and synthetic explanations analysed in the first, theoretical part of the paper - simple descriptions, analogies drawn by visible and person-related similarities, verbalisms, and incomplete, contradictory and scientific explanations (see Table 1). It means that the types of everyday thinking and explanations, coming from a developmentally earlier stage, exist even after children have learnt scientific knowledge in school. As many as up to a quarter of children gave everyday level answers to some questions. 
Likewise, we found a relatively great variety in answers - different types and levels of answers were given to different questions. In frequent occasions, children simply did not answer to more complicated (unusual, novel) questions. These results are relatively concordant with those described in earlier studies where schoolchildren had also given both everyday and synthetic explanations (see Driver \& Squires et al. 1994; Henriques 2000; Taiwo \& Motswiri et al. 1999). However, some of our results differ from these which may be conditioned by cultural or educational peculiarities, and also by a slightly different wording of questions.

The age at which the majority of children's answers are mainly scientific, varies between studies. The reasons may be related to the content of school education and methods used in teaching children. For instance, Bar (1989) found in a study carried out in Israel, that in the beginning of school, children's answers were mainly synthetic but that 9-year-olds and older children provided already mainly scientific explanations. In contrast, in Botswana, even 7th grade pupils gave mainly synthetic and everyday explanations (Taiwo \& Motswiri et al. 1999). Explanations of Estonian children also tended to be more everyday and synthetic than scientific (see Tables 2-4). It means that children have not obtained knowledge about clouds and rain via learning the topic briefly, on one occasion during their second grade. Henriques (2000) argues that several explanations may also develop during the learning process in classroom (e.g., evaporation of water is usually demonstrated by boiling) or making works of art (clouds are made of cotton wool), however, such answers were already given by kindergarten children (in Estonia, such answers were found by Marken, unpublished data). Definitely, the way the topic is taught in the classroom may influence children's understanding and explanations. Similarly, using an analogy (e.g. using cotton in experiments) may even cause misconceptions (how misconceptions about gravity can be generated when using a magnet in demonstrations, see Hannust \& Kikas 2007). At the same time, it should be stressed that children also develop their explanations using analogies in daily life (when water boils vapour rises up, smoke rises from chimneys, clouds remind cotton etc.). However, one should not see a direct transfer in these answers (if cloud is from cotton in artwork $\rightarrow$ then all clouds are made of cotton), but indirect deducing by using (getting help from) visible analogy, which, in reality, many people do to understand a certain phenomena. However, in school education, it is worthwhile to think of how to teach information in different ways, and give time for discussions and the conceptualisation of knowledge (see also Vosniadou \& Ioannides et al. 2001).

One striking peculiarity in the answers of Estonian children was that they gave very few religious explanations for rain and none when talking about clouds and the rainbow. Only rain was related to God or angels (e.g. "it is 
raining when God is sad", "rain is angels' tears"). Piaget $(1930,1954)$ found religious explanations mainly in preschool children. Taiwo and colleagues (Taiwo \& Motswiri et al. 1999), when interviewing fourth to seventh grade children in Botswana, found in addition to everyday explanations by analogy (e.g. "clouds are made of smoke") a variety of religious explanations ("God has made clouds and determines rain", "God makes the rainbow"; "the rainbow shows that God is happy"; "God shows through the rainbow that there will be no rain any more"). Here, the role of cultural context is indeed visible, however, it affects the content of children's answers rather than their form (type of answers). Piaget (1954) related religious explanations of young children with the peculiarities of their thinking - namely, with their egocentrism (i.e., they use analogy with themselves). Other people take care of a child and therefore he/she draws an analogy and thinks that someone has to take care of other things as well. In cultures where the role of God is important (e.g. Botswana), it is God, in other cultures (e.g. Estonia) someone else. For instance, in Estonia, children referred to someone who puts rain into clouds as "someone" "the Sun", but not God. Everyday level thinking and drawing person-oriented analogies is visible in both cultures (see also Toomela 2003; Vygotsky 1934/1997).

In the majority of earlier studies (see Henriques 2000) children were asked generally "What are clouds made of?". It may be that it was easier for children to answer this question than the questions about the specific types of clouds in our study. The relevant general knowledge is taught in school and children might simply repeat the information. However, specific clouds look different, and therefore, children may be in difficulties, when applying the general knowledge learnt in school, "clouds are made of vapour", in the case of specific clouds. It was also visible in our study that the content of children's answers was influenced by the appearance of the clouds (e.g., cumulus was thought to be made of cotton). Also, different answers given to three types of clouds might be caused by children's belief that when someone asks the same question several times one should answer differently (i.e., the first answer was wrong).

The number of correct answers given to different questions about the rainbow varied a lot. In concordance with what children have heard already in childhood, the majority of children knew that the rainbow becomes visible when the Sun is shining and it is raining. It may be one of the verbalisms that everyone knows but does not elaborate on (e.g. from where, how do colours come into the sky?). Actually, without knowing the laws of optics, it is impossible to understand the mechanism of forming colours. Children have different non-scientific explanations concerning light and colours. For instance, primary school children do not know that light source influences (changes) the colour of objects and instead they think that colour is a characteristic of the object and not associated with light shining on the object (e.g. Guesne 1985). 
The majority of answers about the formation of colours and the role of the Sun and rain in this process were synthetic. Besides, children quite quickly tended to answer "I don't know". In reality, we asked about the phenomenon that children could only guess. Some children really tried hard to find the reasons, and referred both to the role of light and raindrops. These explanations were relatively diverse. Such a variety in children's answers (for the rainbow, e.g., "the rainbow is formed after rain with heavy wind", "different colours of rainbow are formed in different raindrops", "the rainbow shows that there is no water in the atmosphere any more") were found in Botswana as well (Taiwo \& Motswiri et al. 1999). Researchers explained this variety with different levels of school education in town and countryside, and also with the importance of religious myths in the country.

Studies about weather add information regarding conceptual development, specifically on the development of everyday, synthetic and scientific explanations in young children as well as schoolchildren; in earlier studies the relevant subject matter has been shown in the case of topics such as astronomy, physics, biology (see Brewer 2008; Brown \& Hammer 2008; Inagaki \& Hatano 2008; Kikas 2005). These explanations give information about the peculiarities of thinking and about the reasons why children struggle with interpreting the phenomena.

\section{ACKNOWLEDGEMENTS}

Writing of this article has been supported by the Estonian Science Foundation (grant no. 7388). Data was collected by Sigrid Kruus, Tiivi Marken, and Elina Malleus.

\section{REFERENCES}

Ackerman, Phillip \& Beier, Margaret 2006. Determinants of Domain Knowledge and Independent Study Learning in an Adult Sample. Journal of Educational Psychology, Vol. 98, No. 2, pp. 366-381.

Bar, Varda 1989. Children's views about the water cycle. Science Education, Vol. 73, No. 4, pp. 481-500.

Brewer, William 2008. Naïve theories of observational astronomy: Review, analysis, and theoretical implications. In: S. Vosniadou (ed.) International handbook of research on conceptual change. New York: Routledge. pp. 155-204

Brown, D. \& Hammer, D. 2008. Conceptual change in physics. In S. Vosniadou (ed.) International handbook of research on conceptual change, pp. 127-153. New York: Routledge.

Chinn, Clark \& Brewer, William 2000. Knowledge Change in Response to Data in Science, Religion and Magic. In: K. Rosengren \& C. Johnson \& P. Harris (eds.) 
Imagining the Impossible: Magical, Scientific, and Religious Thinking in Children. New York: Cambridge University Press, pp. 334-371.

Chinn, Clark \& Malhotra, Betina 2002. Children's responses to anomalous scientific data: How is conceptual change impeded? Journal of Educational Psychology, Vol. 94, No. 2, pp. 327-343.

Driver, Rosalind \& Squires, Ann \& Rushworth, Peter \& Wood-Robinson, Valerie (eds.) 1994. Making Sense of Secondary Science: Research into Children's Ideas. Support Materials for Teachers. London \& New York: Routledge.

Elvisto, Tiina \& Kuurme, Mart \& Laug, Vahur \& Maaste, Kadri 2002. Loodusõpetus. Tööraamat 2.klassile. [Nature studies workbook for grade 2. Part 2.] Tallinn: AS BIT.

Glynn, Shawn \& Duit, Rene (comp.) 1995. Learning Science in the Schools. Mahwah (New Jersey): Erlbaum.

Guesne, Edith 1985. Light. In: R. Driver, E. Guesne \& A. Tiberghien (eds.) Children's Ideas in Science. Milton Keynes, UK: Open University Press, pp. 11-32.

Hannust, Triin \& Kikas, Eve 2007. Children's knowledge of astronomy and its change in the course of learning. Early Childhood Research Quarterly, Vol. 22, pp. 89104.

Henriques, Laura 2000. Children's misconceptions about weather: A review of the literature. Paper presented at the annual meeting of the National Association of Research in Science Teaching, New Orleans, LA, April 29. http://www.csulb.edu/ lhenriqu/NARST2000.htm, last accessed on 24 March 2009.

Inagaki, K. \& Hatano, G. 2008. Conceptual change in naïve biology. In S. Vosniadou (ed.) International handbook of research on conceptual change, pp. 240-262. New York: Routledge.

Jürissaar, Milvi (s.a.). Pilvede klassifikatsioon ja põhiliigid. [Classification and main types of clouds.] http://www.ut.ee/REAM/pilveduus.htm, last accessed on 28 Apr 2009. No longer accessible.

Kendeou, Panayiota \& van den Broek, Paul 2005. The Effects of Readers' Misconceptions on Comprehension of Scientific Text. Journal of Educational Psychology, Vol. 97, No. 2, pp. 235-245.

Kikas, Eve 2003. Constructing Knowledge beyond Senses: Worlds too Big and Small to See. In: A. Toomela (ed.) Cultural Guidance in the Development of the Human Mind. Westport, CT \& London: Ablex, pp. 211-227.

Kikas, Eve 2004. Teachers' Conceptions and Misconceptions Concerning Three Natural Phenomena. Journal of Research in Science Teaching, Vol. 5, pp. 432-448.

Kikas, Eve 2005. Laste teadmiste ja seletuste areng. Taevas, Maa ja päike laste seletustes. [The Development of Children's Knowledge: The Sky, the Earth and the Sun in Children's Explanations.] Mäetagused, Vol. 30, pp. 33-58.

Loks, Marge \& Loks, Üllar 2003. Loodusõpetuse tööraamat 2.klassile. 2.osa. [Nature studies workbook for grade 2. Part 2.] Tallinn: Koolibri.

Nelson, Katherine 2003. Making Sense in the World of Symbols. In: A. Toomela (ed.) Cultural Guidance in the Development of the Human Mind. Westport, CT \& London: Ablex, pp. 139-158.

Nelson, Katherine 2007. Young minds in social worlds. Experience, meaning, and memory. Cambridge, MA \& London: Harvard University press. 
Nobes, Gavin \& Martin, Alan \& Panagiotaki, Georgia (2005). The Development of Scientific Understanding of the Earth. British Journal of Developmental Psychology, Vol. 23, No. 1, pp. 47-64.

Optikanähtused [Optical phenomena.] http://et.wikipedia.org/wiki/Optikan\%C3\%A4htused \#Vikerkaar, last accessed on 28 Apr 2009.

Panagiotaki, Georgia, Nobes, Gavin \& Potton, Anita 2008. Mental models and other misconceptions in children's understanding of the Earth. Journal of Experimental Child Psychology, doi:10.1016/j.jecp.2008.10.003.

Piaget, Jean 1954. The Construction of Reality in the Child. New York, USA: Basic Books.

Piaget, Jean 1930. The Child's Conception of Physical Causality. London: Routledge \& Keegan Paul.

Siegler, Robert 1996. Emerging Minds: The Process of Change in Children's Thinking. New York \& Oxford: Oxford University Press.

Siegler, Robert 2007. Cognitive variability. Developmental Science, Vol. 10, No. 1, pp. 104-109.

Straatemeier, Marthe \& van der Maas, Han \& Jansen, Brenda 2008. Children's knowledge of the Earth: A new methodological and statistical approach. Journal of Experimental Child Psychology, Vol. 100, No. 4, pp. 276-296.

Taiwo, A. \& Ray, H. \& Motswiri, M. \& Masene, R. 1999. Perceptions of the water cycle among primary school children in Botswana. International Journal of Science Education, Vol. 21, pp. 413-429.

Toomela, Aaro 2003. Culture as a Semiosphere: On the Role of Culture in the Cultureindividual Relationship. In: I. Josephs (ed.) Dialogicality in Development. Westport, CT: Praeger Publishers, pp. 129-163.

Toomela, Aaro 2000. Stages of mental development: Where to look? Trames: Journal of the Humanities and Social Sciences, Vol. 4, No. 1, pp. 21-52.

Vikerkaar (s.a). http://et.wikipedia.org/wiki/Vikerkaar

Vosniadou, Stella 1994. Capturing and Modeling the Process of Conceptual Change. Learning and Instruction, Vol. 4, pp. 45-69.

Vosniadou, Stella \& Ioannides, Christos \& Dimitrakopoulou, Aggeliki \& Papademetriou, Efi 2001. Designing learning environments to promote conceptual change in science. Learning and Instruction, Vol. 11, pp. 381-419.

Vygotsky, Lev 1931/1983. Ovladenije vnimanijem. [Attention skills.] Sobranie sochinenii, 3. Problemy razvitija psihiki. Moscow: Pedagogika, pp. 205-238.

Vygotsky, Lev 1934/1997. Thought and language. Revised edition of 1986. Cambridge, MA: MIT Press.

Vygotsky, Lev \& Luria, Alexander 1994. The Tool and symbol in child development. In: R. Van der Veer \& J. Valsiner (eds.) The Vygotsky reader. Oxford \& Cambridge: Blackwell, pp. 99-175.

Wellman, Henry \& Hickling, Anne \& Schult, Carolin 1997. Young children's psychological, physical, and biological explanations. In: H. Wellman \& K. Inagaki (eds.) Emergence of core domains of thought: Children's reasoning about physical, psychological, and biological phenomena. San Francisco, CA: Jossey-Bass, pp. $7-$ 25.

Wertsch, James 1998. Mind as Action. New York: Oxford University Press.

Wertsch, James 1991. Voices of the Mind. A Sociocultural Approach to Mediated Action. Cambridge, MA: Harvard University Press. 